chloride) shows the $328, \mu \mu$ band just as the original substance did.

It is known that liver may contain indol-like substances and so it can be understood that in some vitamin A preparations the $572 \mu \mu$ band is the stronger and in others the $610 \mu \mu$ band is the stronger. In fact, we have obtained saponified vitamin A preparations in which the two bands were of equal strength and others in which either the $610 \mu \mu$ band or the $572 \mu \mu$ band was the more intense.

A. EMmeriw.

M. v. EekELen.

L. K. WOLFF.

Laboratory of Hygiene, University, C'trecht.

\section{Effect of Light on the Surface Tension of Boys's Soap Solutions.}

WHILE investigating the phenomenon of the surface tension of different dilutions of Boys's soap solutions $(2.5$ per cent sodium oleate and 25 per cent glycerine in water) I found that, whenever the solution was exposed to light, there was an abrupt but small fall of surface tension of the solution; but when the solution was kept in a cool, dark room, this abrupt change was not noticed during the experiment, if all the other conditions remain the same. ${ }^{1}$

In 1924, Du Nouy ${ }^{2}$ found that the surface tension of colloidal solutions is not constant, but decreases rapidly as a function of time, and concluded that this phenomenon is due to the adsorption of the molecules in suspension, in the surface layers, as a function of time.

I have found now, by two different methods, namely (1) the surface tension balance method ${ }^{3}$ and $(2)$ the weighing method, 4 that the decrease in surface tension is a function of the time for which the solution is exposed to light, and not a mere function of the time as found by Du Nouy. The dark time-that is, the time for which the soap solutions are kept in a cool, dark room - has almost no effect on the surface tension of soap solutions. A possible reason for this is a chemical action, not adsorption in the surface layers alone.

The detailed study of the investigation, with observations, curves, and discussion, will soon appear in the Indian Journal of Physics, Calcutta.

Physics Laboratory, Mohindra College, L. D. Marajan. Patiala, India, July 20.

${ }^{1}$ I. D. Mahajan, " The Surface Tension of Different Dilutions of Boys's Soap-Solution ", Phil. Mag., in press.

"Du Nouy, P. L., "Surface Tensions of Colloidal Solutions and Dimensions of certain Organic Molecules ", Phil. Mag., vol. 48, August 1924, p. 264. A Warren, E. L., "Surface-tension Balance", Phil. Mag., No. 27,

"Properties of Matter", by Poynting and Thomson, p. 161.

\section{Inheritance of Melanism in Moths.}

Is 1926, Prof. J. W. Heslop Harrison and Dr. F. C. Garrett published an account of experiments in which the moth Selenia bilunaria was fed upon haw thorn foliage which had been artificially contaminated with salts of lead and manganese respectively. In the second generation of moths fed upon the treated material, melanic forms appeared, and the melanism afterwards was inherited on Mendelian lines. No melanics appearod in the control moths fed upon untreated foliage.

So important are these results as regards the origin of mutations that a repetition of the experiments was begun at the John Innes Horticultural Institution in 1927. Three families from three different localities have been reared, one for five and two for six inbred. generations. After two generations fed upon un- treated foliage had been raised, in order to ascertain that the material was genetically pure, portions of each family were fed upon foliage treated with lead and manganese respectively, a control portion being also retained on untreated foliage. In all, 1231 control, 1472 lead treated, and 283 manganese treated moths have been reared, and no signs of melanism have appeared in any individual. Analysis showed that the lead, at any rate, was present in the moths of the final generation reared.

A detailed account of the experiments is being prepared for publication; the results, being negative, lead to no immediate conclusions on the hypotheses that had boen advanced to account for the results of Prof. Harrison and Dr. Garrett.

A. W. MoKenny Hughes.

John Innes Horticultural Institution, Sept. 12.

The Structure of the Spectrum Se III.

THE analysis of the spectra Se IV and Se V has been reported by us in a previous paper. ${ }^{1}$ The experimental data described there have led further to the identification of a system of energy-levels characteristic of the spectrum of doubly-ionised selenium. Combinations between the deepest terms $4 s^{2} 4 p^{2},{ }^{3} P$, ${ }^{1} D$ and the terms $4 s^{2} 4 p 5 s^{3} P,{ }^{1} P$ have been established by comparison with the spectra of $\mathrm{Ge} I$ and As II (unpublished data by $K$. R. Rao). About two hundred lines belonging to the spectrum have entered into the scheme. The $4 s^{2} 4 p^{2}$ term-differences are ${ }^{3} P_{0}-{ }^{3} P_{1}=1740,{ }^{3} P_{1}-{ }^{3} P_{2}=2196,{ }^{3} P_{2}-{ }^{1} D_{2}=9095$, the $4 s^{2} 4 p 5 s$ differences are ${ }^{3} P_{0}-{ }^{3} P_{1}=504,{ }^{3} P_{1}-{ }^{3} P_{2}$ $=3610,{ }^{3} P_{2}-{ }^{1} P_{0}=1265$, and $4 s^{2} 4 p^{2}{ }^{3} P_{2}-4 s^{2} 4 p 5 s{ }^{3} P_{2}^{2}$ $=\nu 126454(\lambda=790 \cdot 80)$.

The above work was done partly at the Imperial College, London, and partly at the Physical Laboratory, Uppsala. A full report will be published later.$$
\text { Physikalisch-Technische Reichsanstalt, }
$$$$
\text { K. R. RAO. }
$$

Berlin, Aug. 7.

${ }_{1}^{1}$ Proc. Roy. Soc., vol. 131, p. 154; 1931.

\section{Group-Capt. Martin Flack.}

IN my obituary notice of the late Group-Capt. Martin Flack, I montioned the fact that, "beginning research with Sir Arthur Keith, he discovered anatomically the sinu-auricular node". These words perhaps do not express fully enough the debt which Martin Flack owed to Sir Arthur, who had been searching for such a structure. He put Flack on to the examination of the heart of a mole, which first gave clear evidence of a structure of which he (Sir Arthur) had found some evidences in the human hearts sent to him for examination by Sir James Mackenzie. Flack completed the discovery by experimental evidence, in the case of hearts of living animals.

Sept. 11. LeONARD HiLl.

\section{Radioactivity and Earth Movements.}

IN a notice of my Glasgow lecture on this subject (Nature, Sept. 5, 1931, p. 419) occurs the passage : "Amongst other instructive conclusions are that "we may regard the Pacific crust as being like that of the continents' (p. 570)". As I have already received several invitations to justify this alleged "conclusion", I wish to point out that what I actually wrote was: " we may therefore regard the Pacific crust as being like that of the continents, but with gabbro passing down into amphibolite in place of the sialic upper layer". Arther Holmes. 